\title{
ANÁLISE DO USO DAS TERRAS E DINÂMICAS DA PAISAGEM A CURTO PRAZO NA REGIÃO DO PARQUE NACIONAL SERRA DE ITABAIANA E ÁREAS CIRCUNVIZINHAS
}

\author{
José Lucas Santos ${ }^{(a)}$, Daniel Rodrigues de Lira ${ }^{(\mathrm{b})}$, Cristiano Aprígio dos Santos ${ }^{(\mathrm{c})}$. \\ (a) Departamento de Geografia Itabaiana - Universidade Federal de Sergipe - UFS, rtx010203@gmail.com \\ (b) Departamento de Geografia Itabaiana - Universidade Federal de Sergipe - UFS, dniellira@ gmail.com \\ (c) Departamento de Geografia Itabaiana - Universidade Federal de Sergipe - UFS, aprigeo@gmail.com
}

Eixo: Uso e ocupação das terras e legislação ambiental

\begin{abstract}
Resumo
O presente trabalho possui como área de estudo o Parque Nacional Serra de Itabaiana (PNSI) e áreas circunvizinhas, tem como objetivo a análise do uso das terras e dinâmicas da paisagem a curto prazo. A área encontra-se inserida na microrregião de Itabaiana, situada no agreste central sergipano, no contexto geoambiental do Domo de Itabaiana. Buscou-se referências da ecodinâmica e geossistema na geografia física aplicada para análise ambiental. Foram realizados levantamentos expedito de campo, com visitas orientadas na área considerada. Dos resultados obtidos através do mapeamento de uso das terras através de duas técnicas de geoprocessamento, pode-se constatar os problemas presentes no local ocasionando a destruição não só do patrimônio geológico/geomorfológico como a própria Unidade de Conservação. A presente pesquisa demonstrou-se capaz de contribuir para a análise ambiental apresentando propostas de soluções para os problemas constatados, oferecendo subsídios para práticas sustentáveis no uso de recursos finitos e essenciais para a sociedade.
\end{abstract}

Palavras chave: Parque Nacional Serra de Itabaiana. Paisagem geomorfológica. Uso das terras; Geoprocessamento.

\section{Introdução}

O presente trabalho teve como bases fundamentadoras, o projeto de pesquisa a análise do uso das terras e dinâmicas da paisagem a curto prazo na região do Parque Nacional Serra de Itabaiana (PNSI) e áreas circunvizinhas, e se apresenta como uma proposta de ferramenta capaz de contribuir para o estudo da presente modelagem superficial, somando a outros trabalhos um levantamento de informações relevantes à evolução das paisagens geomorfológicas do estado de Sergipe, sobretudo, estudos sobre o PNSI.

Segundo Cavalcanti (2014), as paisagens seriam: como sendo um conjunto inter-relacionando de formações naturais e antroponaturais, um sistema complexo e herdado de idades geológicas anteriores, ou seja, as serras que compõem o Parque Nacional Serra de Itabaiana são evidências de processos evolutivos e da dinâmica litosférica e seus agentes (endógenos e exógenos) pelos quais essas rochas passaram até ganharem a modelagem que possuem hoje no período do quaternário. 
O estado de Sergipe apresenta basicamente 3 macros unidades de compartimentação geoambientais, sendo elas, Depressão Sertaneja, Domo de Itabaiana e Planícies Costeiras. Cada uma apresentando caraterísticas únicas que as definem dos demais recortes de paisagem que se possam ser feitos. Informações como clima, vegetação, solo são relevantes na medida em que esses elementos têm participação direta com o uso e a ocupação da terra pelo antrópico, sendo assim as diferentes técnicas de geoprocessamento aqui aplicadas visam contruibuir enquanto proposta para tomada de decisões referentes a preservação geoambiental do PNSI.

\section{1 Área de estudo}

A área de estudo envolve uma extensão segundo site do Instituto Chico Mendes de Conservação da Biodiversidade (ICMBio) de 8.024,79 hectares, localizada na porção central do estado de Sergipe, região oriental do nordeste brasileiro, correspondendo à borda leste da superfície de arrasamento (Etchplano) herdada de uma antiga estrutura dômica (domo Batólito), com um comprimento de aproximadamente 54 quilômetros e uma largura de aproximadamente 30 quilômetros. A área em questão está inserida numa Unidade de Conservação (UC), o Parque Nacional Serra de Itabaiana (PNSI) abrangendo aos Municípios de Areia Branca, Itabaiana, Laranjeiras, Itaporanga D'ajuda, Campo do Brito e Malhador, desde que foi criado em 2005. A unidade, Domo de Itabaiana corresponde ao recorte espacial onde a presente pesquisa foi desenvolvida, na qual se localiza no agreste central sergipano e se apresenta como uma paisagem complexa semelhante a superfície de arrasamento da depressão sertaneja, trata-se de um etchplano herdado, e em suas bordas um conjunto de maciços cristalinos residuais, corresponde as Serra da Miaba, Serra do Caju, Serra Comprida, Serra de Itabaiana (borda leste), Serra do Capunga e Serra do Machado, sendo a principal unidade por abranger a Serra de Itabaiana a qual faz parte da UC em apreço, através do mapeamento do uso e ocupação das áreas do PNSI, conforme o mapa de localização a seguir apresentado (Figura 1). 
XVII Simpósio Brasileiro de Geografia Fisica Aplicada

I Congresso Nacional de Geografia Física
OS DESAFIOS DA GEOGRAFIA FÍSICA NA FRONTEIRA DO CONHECIMENTO

Instituto de Geociências - Unicamp

Campinas - SP

28 de Junho à 02 de Julho de 2017

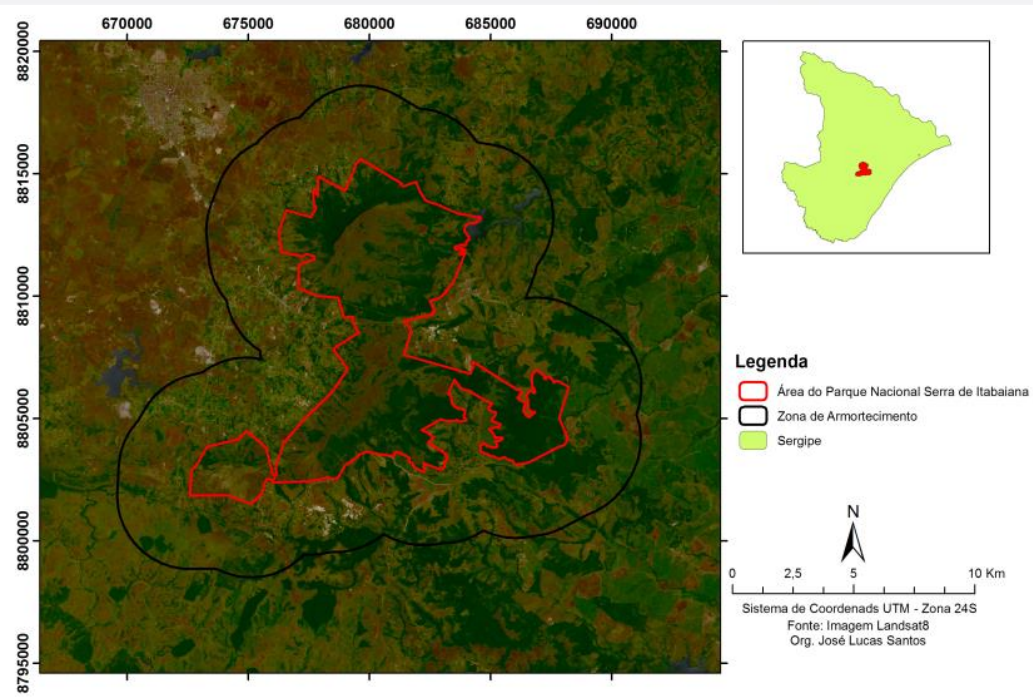

Figura 1 - Mapa de localização

\section{Metodologia}

Para elaboração do mapeamento se fez necessário a aquisição de imagens de satélite para eventual processamento, em ambiente SIG, cabe destacar a utilização do pacote de software para o processamento dos dados deste trabalho o ArcGis, com uso de licença free trial, obtida pelo site da ESRI. A escolha da imagem de satélite Landsat 8 com data 16-11-2015, disponível no site do INPE (Instituto Nacional de Pesquisas Espaciais), se deu pela possibilidade de utilização da Banda 8 pancromática com resolução de 15 metros, que acabou realçando melhor o mapa, no qual foram utilizadas as composições das bandas 7, 6 e 4 (falsa cor), com um realce através da pancromática (banda 8). Desta forma o primeiro mapa (ver figura 02), gerado obedece o método de classificação supervisionada, posteriormente com a mesma imagem foi aplicada a técnica do NDVI, o índice de vegetação normalizada, a mesma consiste na seguinte equação que trabalha com as bandas vermelho e infravermelho próximo, como se segue: NDVI: IVP - V / IVP + V. Como proposta de delimitação da Zona de Amortecimento (ZA) foi adotada a medida de $3 \mathrm{~km}$, tendo em vista a ausência desta no plano de manejo do PNSI e em função dos próprios núcleos urbanos próximos que impossibilitam a adoção de uma ZA maior.

\section{Resultados e Discussão}

Dos produtos cartográficos gerados é possivel observar como a aplicação de diferentes técnicas podem melhorar as informações dadas no mapa de uso das terras, entendo o uso da terra como um processo pelo qual o espaço é ou está sendo ocupado/utilizado, irá refletir em impactos sobre ecossistemas e recursos naturais como água e solo capaz de ser agricultável, segundo Mendonça (1997), a identificação da 


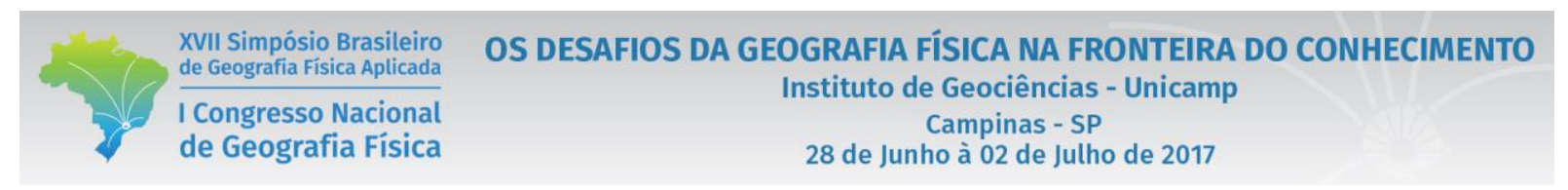

ocupação e uso da terra constitui-se em importantíssimo elemento num estudo ligado ao meio ambiente.

Estudo a fim de gerar informações sobre o uso da terra são importantes, pois podem ser usadas para desenvolver soluções para problemas relacionados a recursos naturais.

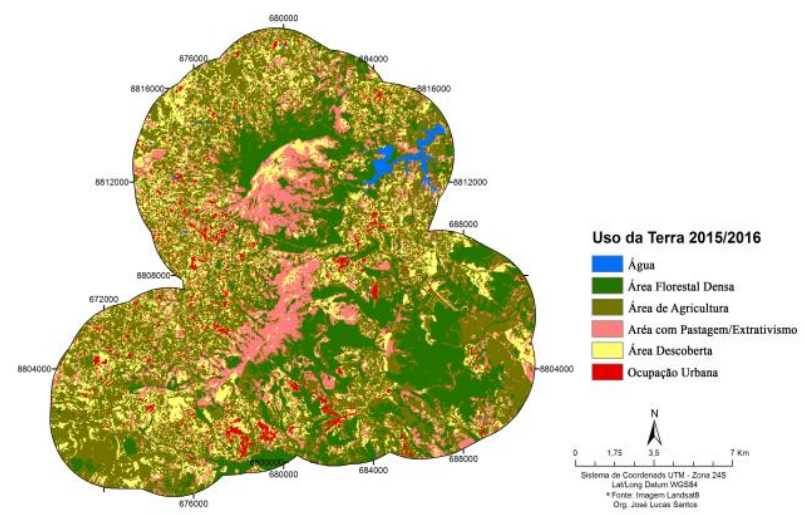

Figura 2 - Mapa Classificação Supervisionada

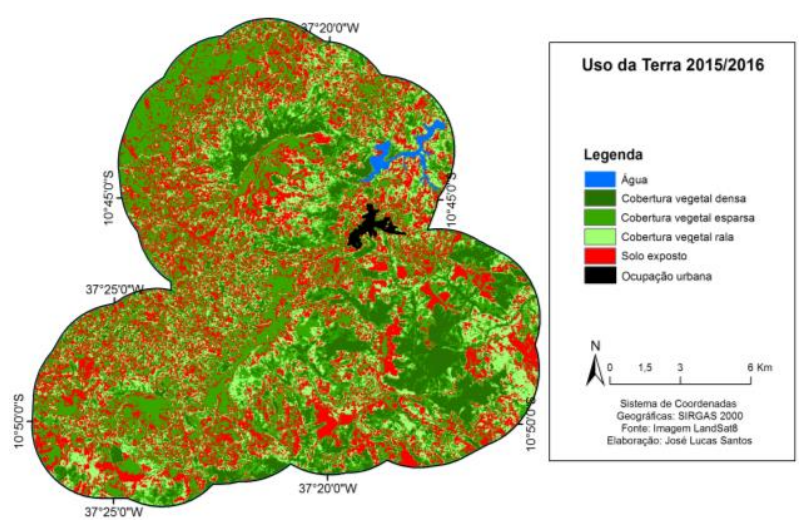

Figura 3 - Mapa NDVI

Com o Mapa 2 (Figura 2), o Método de Classificação Supervisionada (MCS) as áreas marcadas correpondem respectivamente os valores na Quadro 1, bem como a Quadro 2 referente ao Mapa (figura 3), com o NDVI.

PNSI. Quadro 1 - Percentual de áreas (MCS).

\begin{tabular}{|l|l|}
\hline Água & $1,03 \%$ \\
\hline Área Florestal densa & $13,92 \%$ \\
\hline Área Pastagem/extrativismo & $10,53 \%$ \\
\hline Área de Agricutura & $50,76 \%$ \\
\hline Área Descoberta & $20,05 \%$ \\
\hline Ocupação Urbana & $3,71 \%$ \\
\hline
\end{tabular}

PNSI. Quadro 2 - Percentual de areas (NDVI).

\begin{tabular}{|l|l|}
\hline Água & $0,63 \%$ \\
\hline Cobertura vegetal densa & $12,49 \%$ \\
\hline Cobertura esparsa & $38,00 \%$ \\
\hline Cobertura vegetal rala & $19,38 \%$ \\
\hline Solo exposto & $29,10 \%$ \\
\hline Ocupação Urbana & $0,40 \%$ \\
\hline
\end{tabular}

São nítidas as pequenas variações ocorridas com a aplicação de diferentes técnicas, embora os resultados não demonstrem grandes variabilidades quando comparamos a cobertura vegetal densa com a área florestal densa, podemos observar que os problemas referentes a UC, tornam-se evidentes com esses valores obtidos, um exemplo pode ser conferido na Figura 4. 


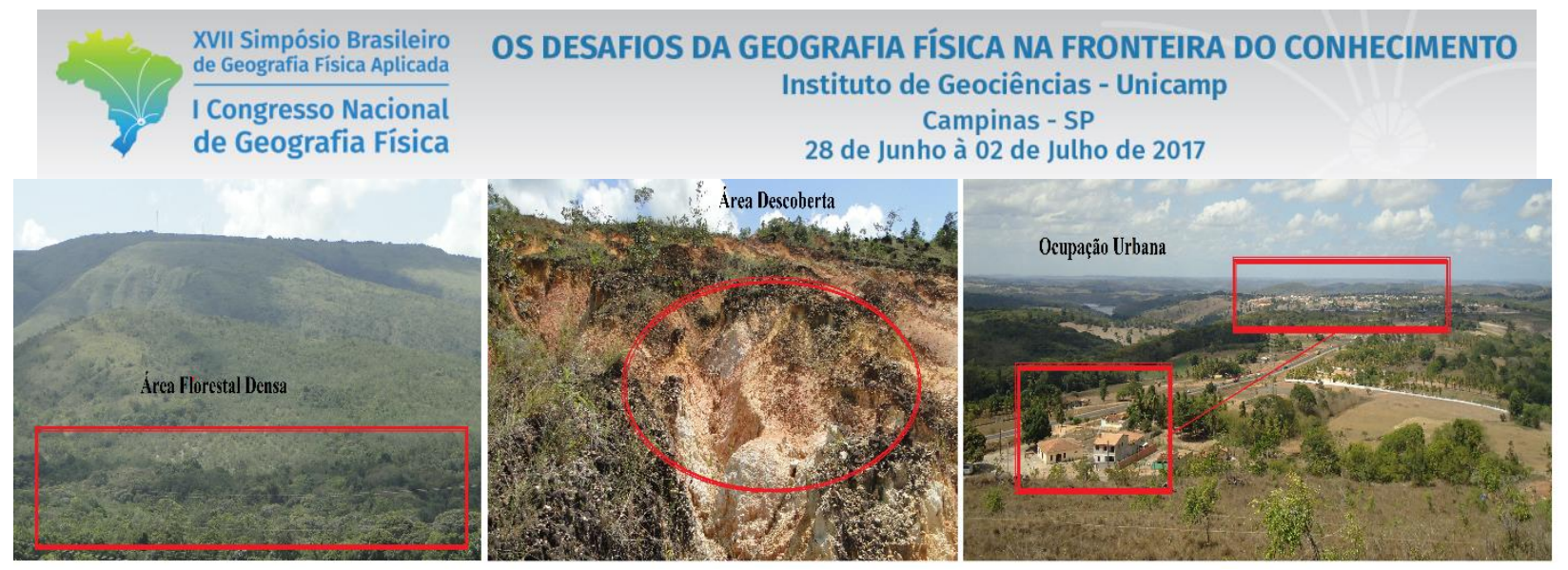

Figura 4. Destaques das tipologias do mapa de uso das terras. Fonte: Autor.

\section{Considerações Finais}

O presente trabalho representa o recorte de paisagem com o cenário de uso das terras no PNSI e áreas circunvizinhas, demonstrando não só os problemas mais frequentes a serem ainda solucionados, que variam desde a ocupação irregular até a extração de recursos naturais. Esta problemática se apresenta como um desafio para o Plano de Manejo que ainda não dispõe de uma delimitação da Zona de Amortecimento, de acordo com a portaria publicada no Diário Oficial onde será decidida futuramente. Como conclusões finais destaca-se: a necessidade de criação da Zona de Amortecimento, uma vez que a extensão territorial abrangida pela área em estudo condiciona a existência de problemas e potencialidades cujos limites estão relacionados a variáveis naturais sendo assim importante delimitar o perímetro da ZA; evidencia-se também a necessidade de desvincular o desenvolvimento econômico local a atividade agrícola e buscar alternativas que promovam o desenvolvimento sustentável dos recursos naturais disponíveis; a necessidade de racionalizar a exploração dos recursos, junto com o controle e desenvolvimento de atividades de recuperação de áreas já degradadas.

\section{Agradecimentos}

Agradeço aos meus orientadores e colegas, ao Grupo de Pesquisa em Geomorfologia do Quaternário Continental e Modelagem Ambiental (QUACOMA), a Coordenação de Pesquisa (COPES), órgão da PróReitoria de Pós-Graduação e Pesquisa (POSGRAP) da Universidade Federal de Sergipe (UFS), pelo apoio financeiro para realização do trabalho (PIBIC-COPES).

\section{Bibliografia}

CAVALCANTI, Lucas Costa de Souza. Cartografia de paisagens: fundamentos / Lucas Costa de Souza Cavalcanti. São Paulo: Oficina de Textos, 2014. 

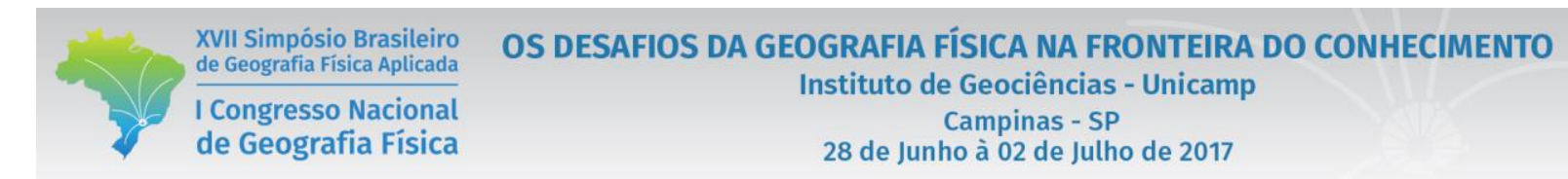

DECISÃO - Serra de Itabaiana - notícia, disponível em: <

https://www.jfse.jus.br/nsistemas/sis_diversos/_lib/file/doc/decisaoserra.pdf > Acessado em 24/07/16.

ICMBio Ministério do Meio Ambiente. Aprovado plano de manejo do parque Serra de Itabaiana. Publicado: 21 de Julho de 2016. Disponível em: <http://www.icmbio.gov.br/portal/ultimas-noticias/20-geral/8036-aprovado-plano-demanejo-do-parque-nacional-serra-de-itabaiana $>$.

Imagem Landsat 8, INPE - Instituto Nacional de Pesquisas Espaciais. Catálogo de imagens. Disponível em: $<$ http://www.dgi.inpe.br/CDSR/>.

Instituto Brasileiro de Geografia e Estatística - IBGE Diretoria de Geociências Coordenação de Recursos Naturais e Estudos Ambientais. Manual Técnico de Uso da Terra. Elaboração do arquivo PDF, Roberto Cavararo. Rio de Janeiro 2013. 171p.

MENDONÇA, F. et al. 1997. O espaço geográfico em análise. IN: RA’E GA. v.1 Departamento de Geografia/UFPR, Curitiba, Brasil.

NORA, Eloi L. D.; MOREIRA, Maurício A.; SANTOS, Cristiano A. dos. Análise da dinâmica de usos e ocupação da terra no Município de Maravilha - SC através de imagens de satélite e geoprocessamento. Anais XIV Simpósio Brasileiro de Sensoriamento Remoto. Natal. Brasil. 25-30 abril 2009. INPE. p. 5725-5731.

RIBEIRO, G. N., FRANCISCO, P. R. M., NETO, J. M. M. e ARAGÃO K. P. Análise temporal da vegetação de Caatinga utilizando NDVI. Revista Educação Agrícola Superior, Associação Brasileira de Educação Agrícola Superior - ABEAS - v.29, n.1, p.3-6, 2014.

SILVA, C. S. da. Aplicação de NDVI para o diagnóstico da degradação e técnicas de manejo para a conservação do bioma Caatinga nos municípios de Frei Paulo e Pinhão - SE. Revista Equador (UFPI), Vol. 4, No 3, (2015). Edição Especial XVI Simpósio Brasileiro de Geografia Física Aplicada. Teresina- Piauí.

SUGUIO, Kenitiro. A Importância da Geomorfologia em Geociências e áreas afins. Revista Brasileira de Geomorfologia, volume 1, No 1 (2000), p.80-87. 